\title{
ANALISA BIAYA PENGOBATAN DEMAM TIFOID BERDASARKAN CLINICAL PATHWAY DI RUMAH SAKIT HARAPAN BUNDA
}

\author{
Pieter Hazmen, ${ }^{1}$ Shirly Kumala, ${ }^{2}$ Prih Sarnianto ${ }^{3}$ \\ ${ }^{1,2,3}$ Fakultas Farmasi Universitas Pancasila, Jakarta, Indonesia \\ Email : hazmenpieter@gmail.com
}

\begin{abstract}
ABSTRAK
Clinical pathway digunakan dalam kendali mutu dan biaya dengan indikator lama rawat. Kasus demam tifoid di Rumah Sakit Harapan Bunda termasuk kriteria High Volume peringkat pertama tahun 2018 dan Problem Prone dalam biaya pengobatan. Tujuan penelitian melakukan analisis biaya pengobatan berdasarkan implementasi clinical pathway pada terapi antibiotik. Penelitian bersifat observasional dengan studi perbandingan pengunaan antibiotik injeksi berdasarkan implementasi clinical pathway. Pengambilan data secara retrospektif dengan variabel dependent outcome terapi (biaya dan lama rawat) sedangkan variabel independent regimen penggunaan antibiotik. Populasi pasien demam tifoid sesuai kriteria implementasi clinical pathway kode ICD (A0.10) 571 pasien. Sampel menggunakan total sampling yang memenuhi kreteria inklusi langsung dijadikan sampel dibagi berdasarkan regimen antibiotik terhadap sistem pembayaran, kelompok dengan jumlah sedikit dieksklusikan. Kelompok pengamatan ada 4 yaitu : ceftriaxone generik $(n=52)$ ceftriaxone bermerek $(\mathrm{n}=51)$, cefotaxime generik $(\mathrm{n}=53)$ dan cefotaxime bermerek $(\mathrm{n}=57)$ berjumlah 213 pasien. Hasil uji satatistik lama rawat $(\mathrm{p}>0,05)$ menjelaskan tidak memiliki perbedaan secara siqnifikan, nilai rata-rata $(5,1596)$. Biaya pengobatan cefotaxime generik $(\mathrm{Rp} 4.072 .002,6792)$, ceriakson generik $(\mathrm{Rp} 4.479 .480,4808)$, cefotaxime bermerek (Rp. 6.945.258,3333) dan ceftriakson bermerek (Rp 7.296.933,5686). Kesimpulan berdasarkan $(\mathrm{AMiB})$ antibiotik sistem pembayaran JKN lebih murah dari umum dan antibiotik biaya termurah cefotaxime generik.
\end{abstract}

Kata Kunci: Bermerek; Ceftriaxone; Cefotaxime; Cinical pathway; Demam tifoid; Generik.

\begin{abstract}
Clinical pathways are used in quality and cost control with indicators of length of stay. Cases of typhoid fever at Harapan Bunda Hospital include the criteria for the first rank of High Volume in 2018 and Problem Prone in the cost of treatment. The purpose of the study is to analyze the cost of treatment based on the implementation of clinical pathways in antibiotic therapy. Observational research with comparative studies of the use of injection antibiotics based on clinical pathway implementation. Retrospective data collection with dependent outcome therapy variables (cost and length of stay) while the independent variable regimen of antibiotic use. The population of typhoid fever patients according to the criteria for the implementation of clinical pathway ICD code (A0.10) 571 patients. Samples using total sampling that fulfills the criteria of direct inclusion are made into samples divided by the antibiotic regimen of the payment system, the group with the least amount excluded. There were 4 observation groups: generic ceftriaxone $(n=52)$ branded ceftriaxone $(n=51)$, generic cefotaxime $(n=53)$ and branded cefotaxime $(n=57)$ totaling 213 patients. Satatistic test results of length of stay $(p>0.05)$ explained that they did not have a significant difference, the average value (5.1596). Medical expenses for

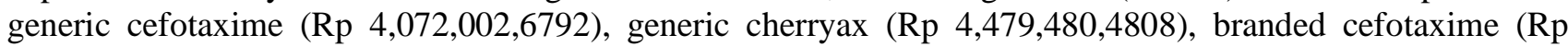
$6,945,258,3333$ ) and branded ceftriaxone (Rp 7,296,933,5686). Conclusions based on JKN (AMiB) antibiotic payment systems are cheaper than general and the cheapest cefotaxime cheapest generic antibiotics.
\end{abstract}

Keywords: Branded; Ceftriaxone; Cefotaxime; Clinical pathway; Typhoid fever; Generic. 


\section{PENDAHULUAN}

Setiap pelayanan kesehatan saling berlomba untuk meningkatkan mutu pelayanan demi mencapai derajat kesehatan yang setinggi-tingginya. Clinical pathway adalah syarat utama kendali mutu dan kendali biaya terutama pada kasus yang berpotensi menghabiskan sumber daya yang besar ${ }^{(1)}$. Setiap rumah sakit yang menyelenggarakan pelayanan rawat inap, umumnya memiliki data statistik sebagai pengukuran mutu pelayanan salah satu indikator mutu tersebut yaitu (Average Length of Stay) rata-rata lama rawat seorang pasien ${ }^{(1)}$. Tujuan utama dalam pelayanan kesehatan menghasilkan outcome terapi yang menguntungkan pasien, provider, dan masyarakat melalui penetapan standar lama rawat dan memilih pola praktek yang terbaik dari berbagai variasi pengobatan ${ }^{(2)}$. Implementasi clinical pathway berhubungan dengan penurunan biaya. Implementasi clinical pathway untuk mewujudkan Tata Kelolah Yang Baik (Good Clinical Governance) dalam meningkatkan kualitas pelayanan dan menurunkan biaya operasional (3). Clinical pathway menjadi salah satu syarat dalam Standar Akreditasi versi Komite Akreditas Rumah Sakit (KARS) 2012 dan Standar Nasional Akreditas Rumah Sakit (SNARS) 2017 edisi 1, sehingga setiap rumah sakit wajib untuk melaksanakan implementasi clinical pathway terutama pada katagori Risiko Tinggi (High Risk), Sering Terjadi (High Volume), dan Rawan Masalah (Problem Prone) $^{(2)}$.

Demam tifoid sering terjadi di beberapa negara di dunia dan umumnya, pada umumnya pada negara dengan tingkat kebersihan rendah. Penyakit ini menjadi masalah kesehatan publik yang signifikan. Hasil WHO (World Health Organisation) memperkirakan jumlah angka insidens di seluruh dunia berkisar 17 juta setiap tahun, dengan jumlah angka kematian sekitar 600.000 dan $70 \%$ nya terjadi di $\mathrm{Asia}^{(4)}$.
Kejadian demam tifoid di negara Indonesia, berkisar sebanyak 60.000 sampai 1.300 .000 kasus, dengan angka kematian 20.000 pertahun ${ }^{(4)(5)}$. Hasil Riskesda tahun 2008 menjelaskan dalam gambaran 10 penyakit terbanyak untuk pasien rawat inap di rumah sakit tahun 2006 persentase demam tifod 3,26\% dengan angka kejadian 72.804 berada pada peringkat ke-3 ${ }^{(6)}$.

Pengobatan demam tifoid dilakukan dengan tatalaksana umum yang bersifat suportif (terapi symtomatik) sesuai dengan gejala yang muncul dan tatalaksana khusus berupa pemberian antibiotik sebagai pengobatan kausal, Penggunaan antibiotik bertujuan tidak terjadi komplikasi yang mengakibatkan kematian, yang tidak kalah penting mencegah kekambuhan (4). Penggunaan antibiotik dalam pengobtan harus efektif dalam segi biaya dan efek terapetik. Antibiotik lini pertama mengatasi demam tifoid adalah chloramphenicol, penisilin dan trimethoprime/sulfametoxsazole. Alternatif lainya adalah golongan sefalosporin (cefotaxime dan ceftriaxone) dan golongan fluoroquinolon (levofloxacine). Terapi antibiotik adalah kelompok yang paling banyak digunakan dalam menyembuhkan penyakit memiliki biaya anggaran yang mencapai $50 \%$ dari obat lain di rumah sakit ${ }^{(7)}$.

Penyakit demam tifoid termasuk 10 besar penyakit rawat inap di Rumah Sakit Harapan Bunda tahun 2018 dengan peringkat pertama, Tingginya kasus demam tifoid sehingga dilakukan implementasi clinical pathway. Implementasi yang sudah diterapkan perlu diukur efektifitasnya dalam menurunkan rata-rata lama rawat untuk menghasilkan outcome terapi yang lebih baik sehingga peneliti tertarik melakukan analisis biaya pengobatan demam tifoid berdasarkan clinical pathway untuk mengetahui terapi antibiotik yang paling efisien dengan prinsip ekonomi kesehatan menggunakan studi farmakoekonomi. 


\section{METODE PENELITIAN}

Penelitian ini bersifat observasional dengan studi perbandingan (comparative study) antara alternatif pengunaan antibiotik injeksi berdasarkan penerapan jalur klinis (clinical pathway). Pengambilan data dalam penelitian ini secara retrospektif pada variabel dependent adalah outcome terapi (biaya dan lama rawat) sedangkan variabel independent regimen penggunaan antibiotik.

Populasi adalah pasien rawat inap dengan kode ICD (International Clasification Of Desease) A0.10 dengan dianogsa demam tifoid sesuai kriteria clinical pathway di Rumah Harapan Bunda tahun 2018. Teknik sampel menggunakan total sampling, semua memenuhi kreteria inklusi langsung dijadikan sampel dalam penelitian ini.

Pada penelitian ini kriteria inklusi adalah pasien yang berumur $\geq 17$ tahun; pasien menggunakan terapi obat antibiotik injeksi sesuai dengan clinical pathway; pasien tanpa perlakuan khusus dan pasien tanpa penyakit penyerta, kriteria eksklusi adalah pasien umur $<17$ tahun;pasien dengan perlakuan khusus;pasien dengan penyakit penyerta;pasien dengan pemberian antibiotik hanya oral; dan pasien dengan pemberian antibiotik tidak sesuai clinical pathway. Kelompok pasien dibagi berdasarkan regimen antibiotik, dan kelompok yang jumlahnya terlalu sedikit dieksklusikan

Analisa biaya pengobtan melalui evaluasi ekonomi kesehatan menggunakan kajian farmakoekonomi dengan metode analisis minimalisasi biaya (AMiB) pada terapi antibiotik terhadap pasien demam tifoid kemudian diolah dan dianalisis untuk diambil kesimpulannya. Data yang diperoleh dilakukan uji statistik dengan uji KruskalWallis dan Uji Mean interval kepercayaan sebesar $95 \%$ dalam bentuk narasi dan tabel.

\section{HASIL PENELITIAN}

Penelitian analisis minimalisasi biaya (AMiB) ini bertujuan melihat biaya pengobatan paling murah sesuai targetnya yaitu efisiensi ekonomi.
Distribusi pasien demam tifoid terhadap kateristik pasien pada kelompok pengamatan meliputi umur, jenis kelamin, pendidikan, perekerjaan, status penikahan, skor tifoid, Nilai tifoid antigen $\mathrm{O}$ (Tabel. 1). 
Tabel 1. Distribusi Pasien Demam Tifoid Berdasarkan Kateristik

\begin{tabular}{|c|c|c|c|c|c|c|}
\hline \multirow[b]{2}{*}{ Kondisi pasien } & \multicolumn{5}{|c|}{$\begin{array}{l}\text { Jumlah (Persentase) } \\
\end{array}$} & \multirow[b]{2}{*}{$p$-value } \\
\hline & $\begin{array}{c}\text { Kelompok } 1 \\
(\mathrm{n}=52)\end{array}$ & $\begin{array}{c}\text { Kelompok } 2 \\
(n=51)\end{array}$ & $\begin{array}{c}\text { Kelompok } 3 \\
(n=53)\end{array}$ & $\begin{array}{c}\text { Kelompok } 4 \\
(n=57)\end{array}$ & $\begin{array}{c}\text { Total } \\
(\mathrm{n}=\mathbf{2 0 4}) \\
\end{array}$ & \\
\hline \multicolumn{7}{|c|}{ Karakteristik Pasien Demam Tifoid } \\
\hline Umur & & & & & & $0,256^{*}$ \\
\hline 17-25 Tahun & $19(36,54 \%)$ & $27(52,94 \%)$ & $26(49,06 \%)$ & $25(43,86 \%)$ & $97(45,54 \%)$ & \\
\hline 26-35 Tahun & $16(30,77 \%)$ & $13(25,49 \%)$ & $15(28,30 \%)$ & $19(33,33 \%)$ & $62(29,11 \%)$ & \\
\hline 36-45 Tahun & $14(26,92 \%)$ & $9(17,65 \%)$ & $10(18,87 \%)$ & $10(17,54 \%)$ & $44(20,66 \%)$ & \\
\hline 46-55 Tahun & $3(5,77 \%)$ & $2(3,92 \%)$ & $2(3,77 \%)$ & $3(5,26 \%)$ & $10(4,69 \%)$ & \\
\hline Jenis kelamin & & & & & & $0,543 *$ \\
\hline Laki-laki & $29(55,77 \%)$ & $30(58,82 \%)$ & $35(66,04 \%)$ & $38(66,76 \%)$ & $132(61,97 \%)$ & \\
\hline Perempuan & $23(44,23 \%)$ & $21(41,18 \%)$ & $18(33,96 \%)$ & $19(33,33 \%)$ & $81(38,03 \%)$ & \\
\hline Pendidikan & & & & & & $0,001 *$ \\
\hline SD/SMP/SMA & $32(61,54 \%)$ & $21(41,18 \%)$ & $38(71,70 \%)$ & $21(36,84 \%)$ & $112(52,58 \%)$ & \\
\hline Perguruan Tinggi & $20(38,46 \%)$ & $30(58,82 \%)$ & $15(28,30 \%)$ & $36(63,16 \%)$ & $101(47,42 \%)$ & \\
\hline Perkerjaan & & & & & & $0,000 *$ \\
\hline Berkerja & $41(78,85 \%)$ & $44(86,27 \%)$ & $36(67,92 \%)$ & $47(82,46 \%)$ & $168(78,87 \%)$ & \\
\hline Belum Berkerja & $11(21,15 \%)$ & $7(13,73 \%)$ & $17(32,08 \%)$ & $10(17,54 \%)$ & $45(21,13 \%)$ & \\
\hline Pernikahan & & & & & & $0,790 *$ \\
\hline Menikah & $29(55,77 \%)$ & $24(47,06 \%)$ & $25(47,17 \%)$ & $31(54,39 \%)$ & $109(51,17 \%)$ & \\
\hline Belum Menikah & $23(44,23 \%)$ & $27(52,94 \%)$ & $28(52,83 \%)$ & $26(45,61 \%)$ & $104(48,83 \%)$ & \\
\hline \multicolumn{7}{|c|}{ Karakteristik penyakit pasien demam tifoid. } \\
\hline Skor Tifoid & & & & & & $0,775 *$ \\
\hline $8-13$ & $45(86,45 \%)$ & $49(96,08 \%)$ & $48(90,57 \%)$ & $56(98,25 \%)$ & $198(92.96 \%)$ & \\
\hline$\geq 13$ & $7(13,46 \%)$ & $2(3,92 \%)$ & $5(9,43 \%)$ & $1(1,75 \%)$ & $15(7,04 \%)$ & \\
\hline Rata-rata & 11,115 & 10,784 & 11,321 & 10,544 & 10,934 & \\
\hline Std. Deviation & 1.78184 & 1.67777 & 1.72386 & 1.60532 & 1.68938 & \\
\hline Nilai Antigen O & & & & & & $0,088 *$ \\
\hline $1 / 160$ & $12(23,08 \%)$ & $24(47,06 \%)$ & $15(23,80 \%)$ & $28(49,12 \%)$ & $79(37,09 \%)$ & \\
\hline $1 / 360$ & $34(65,38 \%)$ & $25(49,02 \%)$ & $35(66,04 \%)$ & $27(47,37 \%)$ & $121(56,81 \%)$ & \\
\hline $1 / 640$ & $6(11,54 \%)$ & $2(3,92 \%)$ & $3(5,66 \%)$ & $2(3,51 \%)$ & $13(6,10 \%)$ & \\
\hline
\end{tabular}

Sumber: Data skunder yang diolah 2019

\section{Uji SPSS Non Parametik Test Kruskal Wallis}

Pengujian dalam penelitian ini menggunakan software Statistical Package for Social Science (SPSS) pada uji KruskalWalli. Analisa statistik menggunakan nilai probabilitas jika $(P<0,05)$ menyatakan maka Ho ditolak dan $\mathrm{H} 1$ diterima sehingga dapat diambil kesimpulan bahwa ada perbedaan terhadap distribusi karekteristik pasien. Pada $(P>0,05)$ menyatakan maka Ho diterima dan H1 ditolak dapat diambil kesimpulan tidak ada perbedaan secara siqnifikan terhadap distribusi pasien pada setiap kelompok pengamatan.

Hasil uji statistik distribusi pasien Pada Tabel I kelompok pengamatan nilai probabilitas $\quad(P<0,05)$ katagori tingkat pendidikan dan katagori perkerjaan yang mejelaskan distribusi pada setiap kelompok pengamatan memiliki berbedaan secara siqnifikan. Pendidkan dalam penelitian ini dibagi menjadi dua katagori sekolah (SD/SMP/SMA) dan perguruan tinggi (DIII/S1/S2). Tingkat pendidikan sekolah 112 pasien $(52,58 \%)$ lebih banyak dibandingkan tingkat pendidikan perguruan tinggi 101 pasien $(47,42 \%)$. Pasien yang dinyatakan berkerja 168 pasien $(78,87 \%)$ lebih banyak dari yang belum berkerja atau tidak berkerja 45 pasien $(21,13 \%)$.

Hasil uji statistik distribusi pasien Pada Tabel I kelompok pengamatan nilai probabilitas $(P->0,05)$ katagori umur, jenis 
kelamin, status perkawinan, score tifoid dan nilai antigen $\mathrm{O}$ distribusi pada setiap kelompok tidak memiliki perbedaan secara signifikan. Gambaran distribusi umur paling banyak usia remaja akhir 91 pasien (45\%) dan terendah umur lansia awal 9 pasien (4\%). Distribusi jenis kelamin paling banyak laki-laki 128 pasien $(33 \%)$ dibandingkan perempuan 76 pasien $(63 \%)$. Pasien dengan status kawin 109 pasien $(51,17 \%)$ lebih banyak dari pasien belum kawin/tidak kawin 104 pasien $(48,83 \%)$. Tingkat keparahan pasien berdasarkan total score dengan nilai rata-rata 10,934 tingkat drajat sedang. Distribusi hasil pemeriksaan antigen $\mathrm{O}$ paling banyak $1 / 320$ berjumlah 121 pasien $(56,81 \%)$, selanjutnya $1 / 60$ berjumlah 79 pasien $(37,09 \%)$ dan yang terakhir $1 / 640$ berjumlah 13 pasien $(6,10 \%)$.

Tabel 2. Distribusi Hasil Terapi Terhadap Kelompok Pengamatan

\begin{tabular}{|c|c|c|c|c|c|}
\hline \multirow[b]{2}{*}{ Hasil Terapi } & \multicolumn{4}{|c|}{ Rata-rata \pm Std. Deviation } & \multirow[b]{2}{*}{$\begin{array}{l}p \text { - } \\
\text { value }\end{array}$} \\
\hline & $\begin{array}{c}\text { Kelompok } 1 \\
(n=52)\end{array}$ & $\begin{array}{c}\text { Kelompok } 2 \\
(n=52)\end{array}$ & $\begin{array}{c}\text { Kelompok } 3 \\
(n=53)\end{array}$ & $\begin{array}{c}\text { Kelompok } 4 \\
(n=57)\end{array}$ & \\
\hline Lama Rawat & $\begin{array}{l}5,3269 \pm \\
1,02366\end{array}$ & $\begin{array}{l}4,9608 \pm \\
0,89355\end{array}$ & $\begin{array}{l}5,3208 \pm \\
0,99564\end{array}$ & $\begin{array}{l}5,0351 \pm \\
0,94425\end{array}$ & $0,148 *$ \\
\hline $\begin{array}{l}\text { Biaya Perbekalan } \\
\text { Farmasi }\end{array}$ & $\begin{array}{l}714201,7115 \pm \\
149833,27461\end{array}$ & $\begin{array}{l}3958241,0196 \pm \\
788340,51312\end{array}$ & $\begin{array}{l}679464,9434 \pm \\
84136,53529\end{array}$ & $\begin{array}{l}3397398,6842 \pm \\
715741,78747\end{array}$ & $\mathbf{0 , 0 0 0 *}$ \\
\hline Biaya Pengobatan & $\begin{array}{l}4479480,4808 \pm \\
887305,46731\end{array}$ & $\begin{array}{l}7296933,5686 \pm \\
1221204,68456\end{array}$ & $\begin{array}{l}4072002,6792 \pm \\
596228,33354\end{array}$ & $\begin{array}{l}6945258,3333 \pm \\
920604,32996\end{array}$ & $\mathbf{0 , 0 0 0 *}$ \\
\hline
\end{tabular}

Sumber : Data skunder yang diolah 2019

Hasil uji satatistik pada lama rawat ( $p>0,05)$ menjelaskan tidak memiliki perbedaan secara siqnifikan lama rawat terhadap setiap kelompok pengamatan rata-rata 5,1596. Nilai rata-rata lama rawat yang paling cepat pada kelompok $2(4,9608)$ hari, peringkat ke kedua kelompok $4(5,0351)$, peringkat ketiga pada kelompok $3 \quad(5,3208)$ dan terakhir pada kelompok 4 (5,3269).

Komponen biaya langsung dalam penelitian ini terdiri dari biaya pengobatan dan biaya perbekalan farmasi berdasarkan harga tarif rumah sakit tahun 2018. Dalam penelitian ini biaya pengobatan adalah seluruh biaya yang dikeluarkan perawatan merupakan penjumlahan dari seluruh biaya yang dibebankan kepada pasien sesuai dengan biling sedangkan biaya perbekalan farmasi merupakan penjumlahan dari biaya obat dan bahan medis habis

Rata-rata biaya perbekelan farmasi $\mathrm{Rp}$ 2.200.338,7320, jika dibandingkan pada setiap kelompok pengmatan yang termurah pada kelompok 3 cefotaxime bermerek JKN sistem pembayatran JKN sebesar Rp. 679.464,9434 selanjutnya kelompok 1 dengan pemberian injeksi ceftriakson generik sistem pembayaran JKN sebesar Rp. 714.201,7115 dilanjutkan kelompok 4 dengan pemberian injeksi cefotaxime bermerek sistem pembayaran asuransi dan tunai sebesar Rp 2.200.338,7320, yang terakhir adalah termahal kelompok 2 dengan pemberian injeksi ceftriakson bermerek sistem pembayaran asuransi dan tunai sebesar Rp 3.958.241,0196. Rata-rata biaya pengobatan Rp. 5.656.442,0094, pada perbandingan untuk setiap kelompok pengmatan yang termurah pada kelompok 3 cefotaxime sistem pembayatran JKN sebesar $\mathrm{Rp}$ 4.072.002,6792 dilanjutkan kelompok 1 ceftriakson generik sistem pembayaran JKN sebesar Rp 4.479.480,4808, disusul kelompok 4 cefotaxime bermerek sistem pembayaran asuransi dan tunai sebesar Rp. 6.945.258,3333 dan yang gtermahal kelompok 2 dengan pemberian injeksi ceftriakson bermerek sistem pembayaran asuransi dan tunai sebesar Rp 7.296.933,5686, keadaan ini dipengaruhi rata-rata rawat inap kelompok terapi sama yaitu 5 hari yang akan mempengaruhi biaya kamar dan vistie dokter. 


\section{PEMBAHASAN}

Perbedaan distribusi pada katagori pendidikan dan perkerjaan tidak mempengaruhi lama rawat pasien hanya berpengaruh terhadap sebaran penyakit. Pasien rawat inap mendapatkan intervensi penuh dari Profesional Pemberi Asuhan berdasarkan clinical pathway. Penelitian sebelumnya menjelaskan pendidikan dan perkerjaan hanya mempengaruhi sebaran demam tifoid karena tingginya aktivitas seseorang dalam kegiatan sehari-hari, menjadi faktor kebiasaan menyukai membeli makanan dan minuman di luar rumah yang kebersihannya tidak dapat dijamin ${ }^{(9)}$.

Pada formulir clinical pathway di Rumah Sakit Harapan Bunda antibitotik ceftriaxone dan cefotaxime ditetapkan menjadi terapi antibiotik injeksi demam tifoid, dari total 204 subyek yang diteliti seluruh subyek sembuh dinyatakan sembuh $100 \%$. Hal tersebut dapat dinilai perkembangannya melalui formulir clinical pathway karena unsur utama yaitu evidence based medicine, penanganan terbaik, dan meningkatkan harapan pasien dengan komunikasi, koordinasi yang dilakukan secara multidisiplin berbagai disiplin ilmu yang diperlukan. Oleh karena itu, pada form clinical pathway terdapat poin proses diagnosa, edukasi kepada pasien, pemberian terapi, keluaran klinis, dan kerja sama antara dokter penanggung jawab, dokter ruangan, apoteker, perawat, dan ahli gizi ${ }^{(2)}$.

Hasil penelitian ini sejalan dengan penelitian sebelumnya bahwa kelompok terapi antibiotik ceftriakson mempunyai lama rawat lebih cepat dibandingkan dengan kelompok terapi antibiotik cefotaxime ${ }^{(10)}$. Faktor lama rawat inap yang cepat disebabkan karena pasien telah memenuhi anjuran untuk istirahat, pengobatan dan nutrisi yang baik sehingga akan mempercepat proses kesembuhan, selain itu oleh faktor karakteristik atau tingkat keparahan penyakit yang tinggi ${ }^{(11)}$. Pada kasus demam tifoid ini, tidak ditemukan pasien yang pulang dengan keadaan meninggal, tetapi pasien pulang dengan keadaan sembuh atas izin dokter. Hal tersebut menunjukkan bahwa perawatan dan pengobatan yang didiberikan selama pasien rawat inap dapat diasumsikan berhasil mesikipun 2 pasien memiliki lebih dari 7 hari sehingga hasil kesesuaian lama rawat berdasarkan clinical pathway $(99,06 \%)$ yang terjadi pada kelompok 1 dan 3 dipengaruhi kondisi berdasarkan tingkat keparahan.

Hasil terapi dari penggunaan antibiotik ceftriaxone dan cefuroxime pada obat bermerk maupun generik menujukan outcome klinis dalam kesembuhan pasien memiliki lama rawat yang setara $(p>0,005)$ sehingga dapat dilakukan analisis minimalisasi biaya (AMiB) dengan melakukan perbandingan pada total biaya. Perhitungan biaya pengobatan demam tifoid berdasarkan clinical pathway dibuat dari sudut pandang provider (rumah sakit) dsenga tujuan agar dapat melihat biaya yang dikeluarkan rumah sakit, sehingga mengetahui komponen dan besar biaya terapi yang dikeluarkan dari setiap pasien $^{(12)}$. Penelitian ini membuktikan penggunaan obat antibiotik injeksi cefotaxime dengan ceftriaxone pada setiap kelompok pengamatan dengan perbedaan sistem pembayaran yang memepengaruhi terhadap pemilihan obat yang digunakan generik atau bermerk tidak berpengaruh secara signifikan untuk lama rawat hanya mempengaruhi total biaya dan tidak ratarata lama perawatan. Hal ini sama dengan penelitian sebelumnya dalam membandingkan kedua obat yang sama dengan perbedaan merk dan harga yang lebih mahal tidak berpengaruh secara signifikan. Cefotaxime dengan ceftriaxone sebagai terapi yang telah ditetapkan dalam clinical pathway demam tifoid di Rumah Harapan Bunda memiliki kemampuan yang sama untuk menghilangkan panas dan gejala ikutan seperti lidah kotor, mual muntah, diare atau obstipasi, serta perut sebah $^{(13)}$.

Hasil Analisis sensitivitas yang digunakan untuk mengetahui bagaimana jika terdapat perubahan nilai pada variabel sehingga tidak tetap. Pada penelitian ini biaya antibiotik terhadap dan lama rawat merupakan variabel yang tidak tetap. Hasil evaluasi farmakoekonomi dari suatu terapi 
atau program kesehatan dapat berubah-ubah atau berbeda waktu dan sensitivitasnya pada asumsi dan parameter spesifik tertentu yang menjadi dasar pada analisis tersebut sehingga dapat disimpulkan bahwa cefotaxime generik memiliki biaya yang paling murah ${ }^{(8)}$.

Keterbatasan ini hanya melakukan analisis biaya pengobatan berdasarkan antibiotik injeksi tidak melibatkan antibiotik oral dan terapi symptoms. Penggunaan antibiotik oral yang digunakan adalah terapi lanjutan antibiotik injeksi pada terapi tifoid adalah golongan sefalosporine (cefixime) dan golongan fluoroquinolone (ciprofloxacin, pefloxacin dan levo levofloxacin) keduanya merupakan terapi yang efektif untuk demam tifoid. Golongan sefalosporine (cefixime) Sefalosporin generasi ketiga yaitu Cefixime mempunyai mekanisme menghambat sintesis dinding sel mikroba ${ }^{(13)}$.

\section{SIMPULAN}

Hasil penelitian ini membuktikan bahwa ratarata lama rawat yang paling cepat pada kelompok ceftriaxone bermerk dan yang paling lama ceftriaxone generik. Total biaya pengobatan pada kelompok cefotaxime dan ceftriaxone generik dengan sistem pembayaran JKN lebih murah dibandingkan cefotaxime dengan ceftriaxone bermerk dengan sistem pembayaran tunai, sedangkan biaya yang paling murah adalah cefotaxime generik.

\section{DAFTAR PUSTAKA}

1. Faradina N, Fadilah N, Budi SC, Iii D, Medis R, Vokasi S. Efektifitas Implementasi Clinical Pathway Terhadap Average Length Of Stay dan Outcomes Pasien DF-DHF Anak di RSUD Kota Yogyakarta. Jkesvo (Jurnal Kesehat Vokasional). 2017;2(2):175-81.

2. Sutoto, DR. Dr. M. Kes, Sudigdo Sastroasmoro. Prof, DR, Dr SpA (K), Wasista Budiwaluyo DM. Panduan Praktik Klinis Dan Clinical Pathway Dalam Asuhan Terintegrasi Sesuai Standar Akreditasi Rumah Sakit 2012. 2015th ed. Jakarta; 2015. 1-216 p.
3. Nimah K, Nurwahyuni A. Evaluasi Implementasi Clinical Pathway Apendisitis Akut Terhadap Tagihan Pasien Di Rumah Sakit " X ." University of Indonesia. 2017;1-20.

4. Rahmasari V, Lestari K. Manajemen Terapi Demam Tifoid: Kajian Terapi Farmakologis Dan Non Farmakologis. J Farmaka. 2018;16(1):184-95.

5. Kemetrian Kesehatan Republik Indonesia. Keputusan Mentri Kesehatan Republik Indonesia Nomor 363/Menkes/SK/V/2006. Jakarta, Indonesia: Menteri Kesehatan Republik Indonesia; 2006 p. 1-41.

6. Raflizar, Holly M. Association of Determinant Factors with Prevalence of Typhoid in Java Ocean. J Ekol Kesehat Vol 9 No 4. 2010;1(1):1357-65.

7. Haluang O, Tjitrosantoso H, Kojong NS. Demam Tifoid Anak Di Instalasi Rawat Inap Rsup Prof . Dr . R . D . Kandou Manado. J Ilm Farm. 2015;4(3):117-25.

8. Kemetrian Kesehatan Republik Indonesia. Pedoman Penerapan Kajian Farmakoekonomi. Drs. Prih Sarnianto, M.Sc A, dr. Zorni Fadia, Erie Gusnellyanti, S.Si, Apt M, editors. Kementrian Kesehatan Republik Indonesia. Jakarta: Kementrian Kesehatan Republik Indonesia; 2013. 31-37 p.

9. Dwi TCA, Musthofa SB. Faktor Faktor Yang Berhubungan Dengan Praktik Hidup Bersih Dan Sehat Sebagai Upaya Pencegahan Demam Tifoid Pada Siswa Di Sdn Genuksari 02 Semarang. J Kesehat Masy. 2018;6(1):826-34.

10. Rosyid A, Santoso A, Andriani IT. Analisis Efektivitas Biaya Pengobatan Penggunaan Sefotaxim Dan Seftriaxon Pada Pasien Demam Tifoid Anak Rawat Inap Di Rumah 
Sakit Islam Sultan Agung Semarang. ISSN- Online $2548 \quad-\quad 3897$. 2018;1(1):31-9.

11. Virdania KV, Laksemi DAAS, Damayanti PAA. Hubungan Umur Dengan Jenis Rawat Dan Lama Hari Rawat Inap Pasien Demam Tifoid Di Rsup Sanglah Denpasar Tahun 2014. EJurnal Med VOL 7 NO7. 2018;7(7):1-7.

12. Jannah N, Ihwan, Tandah MR. Efektifitas Biaya Penggunaan Seftriakson Dan Sefiksim Pada Pasien Demam Tifoid Rawat Inap Di Rsu Anutapura Palu Periode 2015-2017. J Ilm Medicam. 2019;5(1):45-50.

13. Hanifah HZ, Sari IP, Nuryastuti T. Evaluasi Penggunaan Antibiotik Empiris dan Analisis Biaya Demam Tifoid di Sebuah RS Swasta Kota Semarang. J Sains Farm Dan Klin. 2018;5(1):1-6. 